\title{
Article
}

\section{The Effect of Precursor Ligands and Oxidation State in the Synthesis of Bimetallic Nano-Alloys}

Alec P. LaGrow, Kristian Rahbek Knudsen, Noktan M. AlYami, Dalaver H. Anjum, and Osman M. Bakr

Chem. Mater., Just Accepted Manuscript • DOI: 10.1021/acs.chemmater.5b01247 • Publication Date (Web): 12 May 2015

Downloaded from http://pubs.acs.org on May 17, 2015

\section{Just Accepted}

"Just Accepted" manuscripts have been peer-reviewed and accepted for publication. They are posted online prior to technical editing, formatting for publication and author proofing. The American Chemical Society provides "Just Accepted" as a free service to the research community to expedite the dissemination of scientific material as soon as possible after acceptance. "Just Accepted" manuscripts appear in full in PDF format accompanied by an HTML abstract. "Just Accepted" manuscripts have been fully peer reviewed, but should not be considered the official version of record. They are accessible to all readers and citable by the Digital Object Identifier (DOI®). "Just Accepted" is an optional service offered to authors. Therefore, the "Just Accepted" Web site may not include all articles that will be published in the journal. After a manuscript is technically edited and formatted, it will be removed from the "Just Accepted" Web site and published as an ASAP article. Note that technical editing may introduce minor changes to the manuscript text and/or graphics which could affect content, and all legal disclaimers and ethical guidelines that apply to the journal pertain. ACS cannot be held responsible for errors or consequences arising from the use of information contained in these "Just Accepted" manuscripts. 
Controlling the surface structure of metal and metal alloy nanoparticles is critical for their catalytic applications. ${ }^{1-3}$ In catalysis, noble metal alloy nanoparticles have been studied to maximize their catalytic efficiency by selecting the exposed crystal facets for the intended reaction.4-8 The concentration of edge, corner, and facet sites, which are a function of particle size, has been found to have a profound effect on the particle's catalytic activity.9-12 It has been observed that the spatial variation of elements in bimetallic systems affects the nanoparticle's catalytic properties by controlling the surface strain and

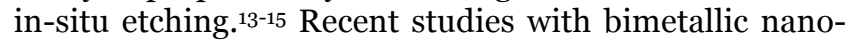
particle systems have shown that the elemental distribution within the alloys is not homogenously distributed. ${ }^{13}$, 16-18 The elemental distribution of the as-prepared alloy nanoparticles is highly dependent on the reaction conditions, including the precursors, ligands, and reduction mechanisms, of both of the components. ${ }^{17-18}$ However, with the recent progress in the investigation of the spatial variation in bimetallic systems, it has become obvious that systematic studies of the reaction conditions and parameters are required to understand their effects on the formation of alloy nanoparticles.

Recent research into de-convoluting the effects of reaction conditions on bimetallic nanoparticles investigated altering the reduction rate of both of the components by controlling the precursor to form core-shell vs. alloy PdPt nanoparticles. ${ }^{18}$ Studies with monometallic systems have examined the effect of precursors and reaction additives on the size and shape of the nanoparticles. These studies have assessed the effect of the added surfactants, ${ }^{19-21}$ the precursor ligands ${ }^{21-22}$ and the oxidation state on the reduction kinetics of the nanoparticles. ${ }^{11}$ Additional systematic studies of individual reaction components for nanomaterials are still needed for researchers to understand the reaction system, particularly for bimetallic nanoparticles.

In this study, we investigated the effects of metal precursors on the formation of shape-controlled platinum alloy nanoparticles via flow chemistry ${ }^{23-25}$ at elevated pressures and super-critical temperatures in toluene. We demonstrate broad control of nanoparticle size, independent of its shape, along with the surface segregation of platinum in the presence of halides. These findings introduce a method for fully scalable size tuning of shape-controlled nanoparticles with a tunable surface structure by controlling the exposed surface facets and the spatial distribution of the bimetallic components. 
Chemicals. Toluene, platinum (IV) chloride (96\%), tungsten carbonyl (97\%), copper (II) chloride (anhydrous, 99.995\%) and nickel (II) bromide hydrate (98\%) were purchased from Sigma Aldrich. Platinum acetylacetonate (98\%), nickel acetylacetonate (95\%), which formed the dihydrate upon use, ${ }^{19}$ copper bromide (98\%), and nickel (II) chloride hexahydrate $(99.9 \%)$ were purchased from STREM. Oleylamine (technical grade, 70\%), 1adamantanecarboxylic acid (99\%), copper (II) acetylacetonate (98\%), platinum (II) bromide (98\%) and nickel (II) chloride hexahydrate (99.9999\%) were purchased from Acros. Platinum (IV) bromide (99.99\%), platinum (II) chloride (98\%) and platinum (IV) iodide (99.95\%) were purchased from Alfa Aesar. Carbon monoxide gas (99.95\%) was purchased from AHG, Specialty Gas Centre, Jeddah, Saudi Arabia. All chemicals were used as delivered without further purification.

Nanoparticle Synthesis. A commercially available flow reactor from Uniqsis Ltd, FlowSyn Multi X was fitted with a $30 \mathrm{~mL}$ Teflon-coated inert stainless steel coil reactor and a 10 bar inert back pressure regulator, both supplied by Uniqsis. A solution of platinum precursor $\left(0.01 \mathrm{~mol} \mathrm{~L}^{-1}\right)$, nickel or copper precursor $\left(0.01 \mathrm{~mol} \mathrm{~L}^{-1}\right)$, 1-adamantane carboxylic acid (0.02 mol L$\left.~^{-1}\right)$, and oleylamine $\left(0.2 \mathrm{~mol} \mathrm{~L}^{-1}\right)$ was dissolved in toluene in a sonicator. This solution was allowed to flow through pump A. A solution of $\mathrm{W}(\mathrm{CO})_{6}$ (0.03 mol L-1) was dissolved in toluene in a sonicator and was allowed to flow through pump B. The reactor was heated to $200{ }^{\circ} \mathrm{C}$, and both of the pumps were set to a flow rate of $2.0 \mathrm{~mL} / \mathrm{min}$. Once the pressure was stable, the reaction was started. The solutions used were not degassed. The two streams entered a mixing device and then continued through the coil reactor at 10 bar. A product stream containing black nanoparticles was collected. After the reaction, the samples were immediately precipitated with ethanol to stop the post-preparative etching with the halides. The product was precipitated with ethanol and centrifuged at 12,000 RPM for $15 \mathrm{~min}$. The supernatant was discarded, and the particles were washed with toluene and ethanol again. The particles were washed three times for bright field imaging, and six times for HAADF-STEM.

The particles synthesized in the presence of carbon monoxide gas used a commercially available Uniqsis Gam II tube-in-tube reactor in the flowstream, which has an inner tube composed of AF-2400 polymer that allows the gas to permeate under a pressure gradient. With the system pressure at 10 bar, a CO gas pressure of 12 bar was applied, thus saturating the solvent with $\mathrm{CO}$.

The particles formed in an oxygen-free environment had the precursor solution degassed before the reaction was run and carried out under flowing nitrogen.

Electron Microscopy. Bright-field transmission electron microscopy (BF-TEM) of the prepared samples was performed with an electron microscope (FEI Company Model Titan $\mathrm{G}^{2}$ 80-300 ST) with an extra-brightness field emission gun (x-FEG) at the accelerating voltage of $300 \mathrm{kV}$. All the size distributions were measured using over 500 particles. For the PtCu samples, the imaging and EDS acquisition were performed on a 400 square mesh nickel grid with a carbon film on top (Electron Microscopy Services). For the PtNi samples, the imaging and EDS acquisition were performed on a 400 square mesh copper grid with a carbon film on top (Electron Microscopy Services). STEM-EDS mapping, tomography and aberration-corrected HAADFSTEM were performed on 200 square mesh thin bar gold grids with carbon film (Electron Microscopy Services).
The energy dispersive X-ray spectroscopy (EDS) ratios and map ratios were obtained on a detector from EDAX, Inc. with a lithium-doped silicon diode, a beryllium window and an optimized solid angle of 0.07 stradians. The detector was cooled with liquid nitrogen. Prior to EDS acquisition, the stage was tilted to its optimized position, +14 degrees, and mapping was performed. The EDS ratios were taken from over a thousand particles, averaging multiple areas for statistical analysis with Titan-ST. HAADF-STEM was performed with a camera length of $100 \mathrm{~mm}$ and a 50 micron C2-aperture.

HAADF-STEM tomography was performed from $-75^{\circ}$ to $75^{\circ}$ with $\mathrm{PtCl}_{4}$ and $\mathrm{CuCl}_{2}$ and from $-70^{\circ}$ to $70^{\circ}$ with $\mathrm{PtBr}_{4}$ and $\mathrm{CuBr}_{2}$. The acquired data were aligned and reconstructed in Inspect3D, and the volume was generated with the simultaneous iterative reconstruction technique (SIRT). The volume-rendering technique was applied to the tomograms for 3-dimensional shape analysis using Avizo-Fire software.

High-resolution STEM (HR-STEM) analysis of the samples was performed on a Titan $\mathrm{G}^{2} 80-300$ ST operating at $300 \mathrm{kV}$ equipped with a spherical aberration corrector (CsCorrector) to achieve HR-STEM analysis with sub-angstrom spatial resolution (o.8 $\AA$ ). Prior to the experiments, the Cscorrector was used to decrease the spherical aberration in the STEM micrographs by reducing the third-order coefficient ( $\mathrm{C}_{3}$ ) of spherical aberration to approximately less than one micron.

X-Ray Diffraction (XRD). XRD patterns were obtained from samples prepared on zero background silicon plates with a Powder XRD Bruker D8 Advance instrument with $\mathrm{Cu} \mathrm{Ka}$ radiation (1.5409 $\AA$ ).

\section{RESULTS AND DISCUSSION}

Reactions were performed to study the effect of metal precursors on the formed nanoparticles. The synthetic methodology was adapted from the work of Zhang et al. ${ }^{6}$ and $\mathrm{Wu}$ et al. ${ }^{26}$ The synthesis of the $\mathrm{Pt}_{3} \mathrm{Ni}$ nanooctahedra was reported by Zhang et al. using $\mathrm{W}(\mathrm{CO})_{6}$ to control the shape of the particles, which was proposed to occur due to the reaction between $\mathrm{W}^{\mathrm{o}}$ and $\mathrm{Pt}^{2+}$ to slowly form $\mathrm{Pt}^{\mathrm{o}}$ in solution, allowing the particles to grow thermodynamically. ${ }^{6}$ The tungsten was reported to stay in solution as $\mathrm{W}^{6+}$ at the end of the reaction and not form an alloy with platinum under their conditions. ${ }^{6,27}$ Subsequently, several groups showed that the major effect of the metal precursors in the synthesis occurred due to the binding of carbon monoxide to the metal surface and changing the stability of the exposed surface facets. ${ }^{26,28-}$ 29 For platinum-nickel and platinum-copper alloys, the $\{111\}$ facet is favored and the octahedra are formed in the presence of $\mathrm{W}(\mathrm{CO})_{6}{ }^{6,} 3^{\circ}$ or carbon monoxide. ${ }^{26} \mathrm{~W}(\mathrm{CO})_{6}$ is thought to dissociate completely under similar reaction conditions and behaves similarly to carbon monoxide gas in nanoparticle syntheses. ${ }^{31} \mathrm{We}$ found that the use of $\mathrm{W}(\mathrm{CO})_{6}$ and $\mathrm{CO}$ gas provided essentially the same results and was needed for the shape control (Figure S1 in the Supporting Information). The oleylamine was originally used as a solvent by Zhang et al. ${ }^{6}$ In this synthesis, oleylamine was reduced to 10 equivalents and 1adamantane carboxylic acid was reduced to 1 equivalent, allowing for the optimized synthesis conditions. The use of 1-Adamantane carboxylic acid reduced both the size and the size distribution of the particles formed (Figure S2). 
Given the unique reaction conditions of the flow reactor, the particles could be produced continuously with a 7.5 minute-residence time. The reactions were run at a pressure of 10 bar to prevent toluene from boiling at 200 ${ }^{\circ} \mathrm{C}$ and to retain the carbon monoxide gas in solution that was generated during the reaction.

The parameters studied were the effect of the ligands and the oxidation state of the precursors on the formed nanomaterials. The chemical environment (oleylamine, 1-adamantane carboxylic acid, tungsten carbonyl and toluene) remained constant, whereas the precursors for the platinum and nickel or copper were changed from acetylacetonates to chlorides to bromides. The platinum halide precursors were also studied according to the Pt(II) and Pt(IV) oxidation states. The particle edge length was determined by measuring along the $\{111\}$ facet, and the composition was determined by energy dispersive X-ray spectroscopy (EDS). The PtNi alloy particles formed with platinum acetylacetonate $\left[\mathrm{Pt}(\mathrm{acac})_{2}\right]$ and nickel acetylacetonate dihydrate $\left[\mathrm{Ni}(\mathrm{acac})_{2} .2 \mathrm{H}_{2} \mathrm{O}\right]$ were $4.5 \pm 0.6 \mathrm{~nm}\left(\sim \mathrm{Pt}_{57} \mathrm{Ni}_{43}\right)$ nano-octahedra (Figure 1 A and SI Figure $\mathrm{S}_{3}$ ). The particles formed with the chlorides with $\mathrm{NiCl}_{2} \cdot 6 \mathrm{H}_{2} \mathrm{O}$ and $\mathrm{PtCl}_{2}$ were $6.2 \pm 0.8 \mathrm{~nm}$ $\left(\sim \mathrm{Pt}_{40} \mathrm{Ni}_{60}\right)$ nano-octahedra (Figure $1 \mathrm{C}$ and Table $\mathrm{S} 1$ ), and with $\mathrm{NiCl}_{2} \cdot 6 \mathrm{H}_{2} \mathrm{O}$ and $\mathrm{PtCl}_{4}$, the formed particles were $9 \pm 1 \mathrm{~nm}\left(\sim \mathrm{Pt}_{46} \mathrm{Ni}_{54}\right)$ nano-octahedra (Figure $\left.1 \mathrm{E}\right)$. For the bromides, the particles formed with $\mathrm{NiBr}_{2} \cdot 2 \mathrm{H}_{2} \mathrm{O}$ and $\mathrm{PtBr}_{2}$ and with $\mathrm{NiBr}_{2} \cdot 2 \mathrm{H}_{2} \mathrm{O}$ and $\mathrm{PtBr}_{4}$ were $11 \pm 2$ $\mathrm{nm}$ nano-octahedra with EDS ratios of $\sim \mathrm{Pt}_{36} \mathrm{Ni}_{64}$ and $\sim \mathrm{Pt}_{40} \mathrm{Ni}_{60}$, respectively (Figure $1 \mathrm{G}$ and $\mathrm{I}$ ). The particles formed with $\mathrm{PtCu}$ using platinum acetylacetonate and copper acetylacetonate $\left[\mathrm{Cu}(\mathrm{acac})_{2}\right]$ as the precursors were $3.6 \pm 0.6 \mathrm{~nm}\left(\sim \mathrm{Pt}_{39} \mathrm{Cu}_{61}\right)$ nano-octahedra (Figure 1 B). Using the chloride precursors, the particles were $13 \pm$ $2 \mathrm{~nm}\left(\sim \mathrm{Pt}_{45} \mathrm{Cu}_{55}\right)$ nano-octahedra with $\mathrm{CuCl}_{2}$ and $\mathrm{PtCl}_{2}$ (Figure $1 \mathrm{D})$ and $13 \pm 1 \mathrm{~nm}\left(\sim \mathrm{Pt}_{40} \mathrm{Cu}_{60}\right)$ nano-octahedra with $\mathrm{CuCl}_{2}$ and $\mathrm{PtCl}_{4}$ (Figure $1 \mathrm{~F}$ ). With the bromide precursors, the particles were $14 \pm 1 \mathrm{~nm}\left(\sim \mathrm{Pt}_{39} \mathrm{Cu}_{61}\right)$ nanooctahedra with $\mathrm{CuBr}_{2}$ and $\mathrm{PtBr}_{2}$ (Figure $1 \mathrm{H}$ ), and with $\mathrm{CuBr}_{2}$ and $\mathrm{PtBr}_{4}$, the particles were $16 \pm 1 \mathrm{~nm}\left(\sim \mathrm{Pt}_{34} \mathrm{Cu}_{66}\right)$ nano-octahedra with some deformation (Figure $1 \mathrm{~J}$ ). $\mathrm{PtCu}$ and PtNi show a general increase in particle size in order from the acetylacetonate precursors to the chloride precursors and then to the bromide precursors. The average composition became more nickel rich with the halide precursors (Table $\mathrm{S} 1$ ), and the $\mathrm{PtCu}$ varied around $\mathrm{Pt}_{40} \mathrm{Cu}_{60}$ (Table S2).
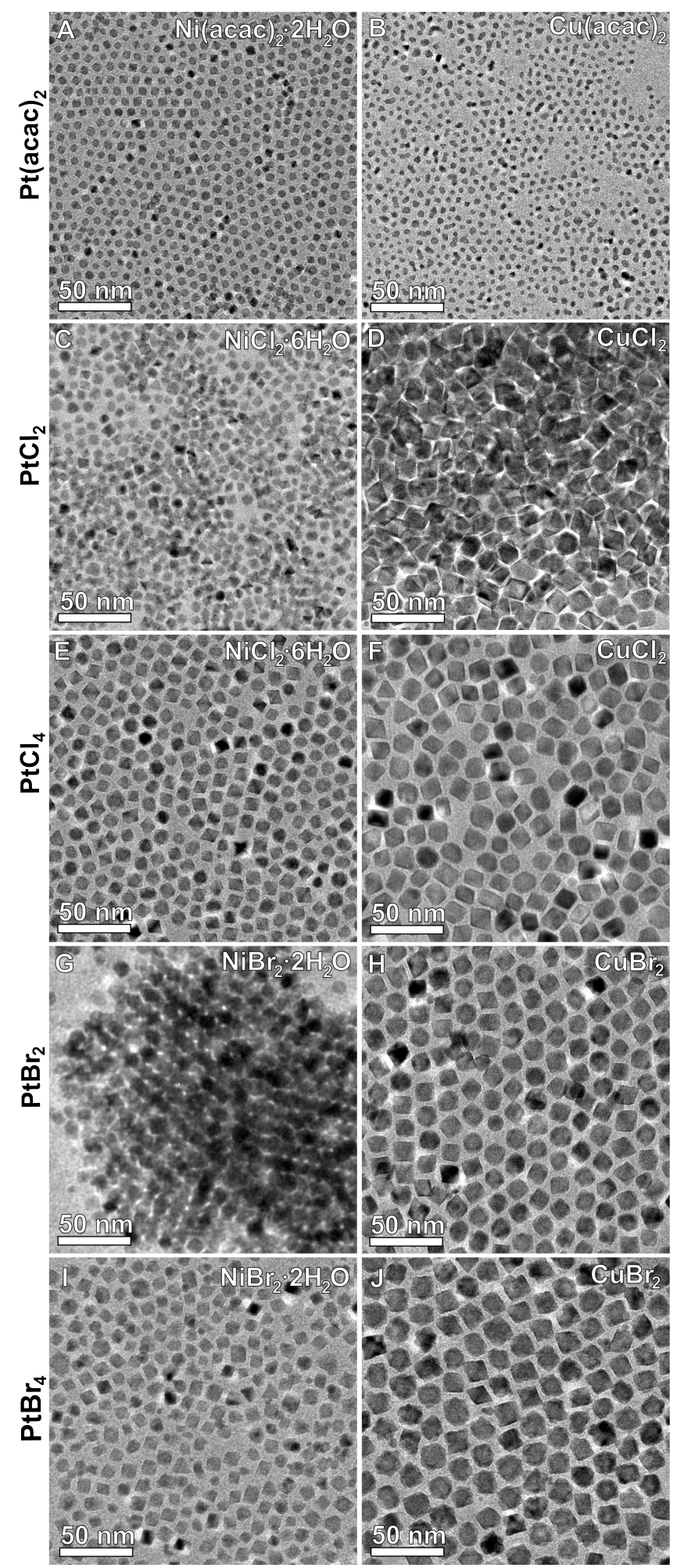

Figure 1. Bright-field TEM micrographs of PtNi nanoparticles formed with A) $\mathrm{Pt}(\text { acac) })_{2}$ and $\mathrm{Ni}(\mathrm{acac})_{2} \cdot 2 \mathrm{H}_{2} \mathrm{O}$, C) $\mathrm{PtCl}_{2}$ and $\mathrm{NiCl}_{2} \cdot 6 \mathrm{H}_{2} \mathrm{O}$, E) $\mathrm{PtCl}_{4}$ and $\left.\mathrm{NiCl}_{2} \cdot 6 \mathrm{H}_{2} \mathrm{O}, \mathrm{G}\right) \mathrm{PtBr}_{2}$ and $\mathrm{NiBr}_{2} \cdot 2 \mathrm{H}_{2} \mathrm{O}$ and I) $\mathrm{PtBr}_{4}$ and $\mathrm{NiBr}_{2} \cdot 2 \mathrm{H}_{2} \mathrm{O}$. BF-TEM images of $\mathrm{PtCu}$ nanoparticles formed with B) $\mathrm{Pt}(\mathrm{acac})_{2}$ and $\left.\mathrm{Cu}(\mathrm{acac})_{2}, \mathrm{D}\right) \mathrm{PtCl}_{2}$ and $\left.\mathrm{CuCl}_{2}, \mathrm{~F}\right) \mathrm{PtCl}_{4}$ and $\left.\mathrm{CuCl}_{2}, \mathrm{H}\right) \mathrm{PtBr}_{2}$ and $\mathrm{CuBr}_{2}$ and $\left.\mathrm{J}\right) \mathrm{PtBr}_{4}$ and $\mathrm{CuBr}_{2}$.

The formation of octahedra with the different precursors is evident in the high angle annular dark field scan- 
ning transmission electron microscopy (HAADF-STEM) analysis presented in Figure 2. In all cases, the particles were imaged along the [110] zone axes and were bound by the $\{111\}$ facet (Figure $2 \mathrm{~A}-\mathrm{F}$ ). The particles formed with both of the acetylacetonates have no apparent preference in the brightness of the atomic columns beyond the thickness effect (Figure $2 \mathrm{~A}$ and $\mathrm{B}$ ) and appear to be random alloys. ${ }^{16}$ For the particles formed with the halide precursors, a bright outline is visible along the edge atoms of the particles (Figure $2 \mathrm{C}-\mathrm{F}$ ), which is attributed to the atomic contrast. For the $\mathrm{PtCu}$ particles formed with $\mathrm{PtBr}_{4}$ and $\mathrm{CuBr}_{2}$ (PtCu-Br), a surface step is evident, and additional HAADF-STEM micrographs show that there is a higher degree of surface indentation in the samples prepared from bromide precursors (SI Figure S4).
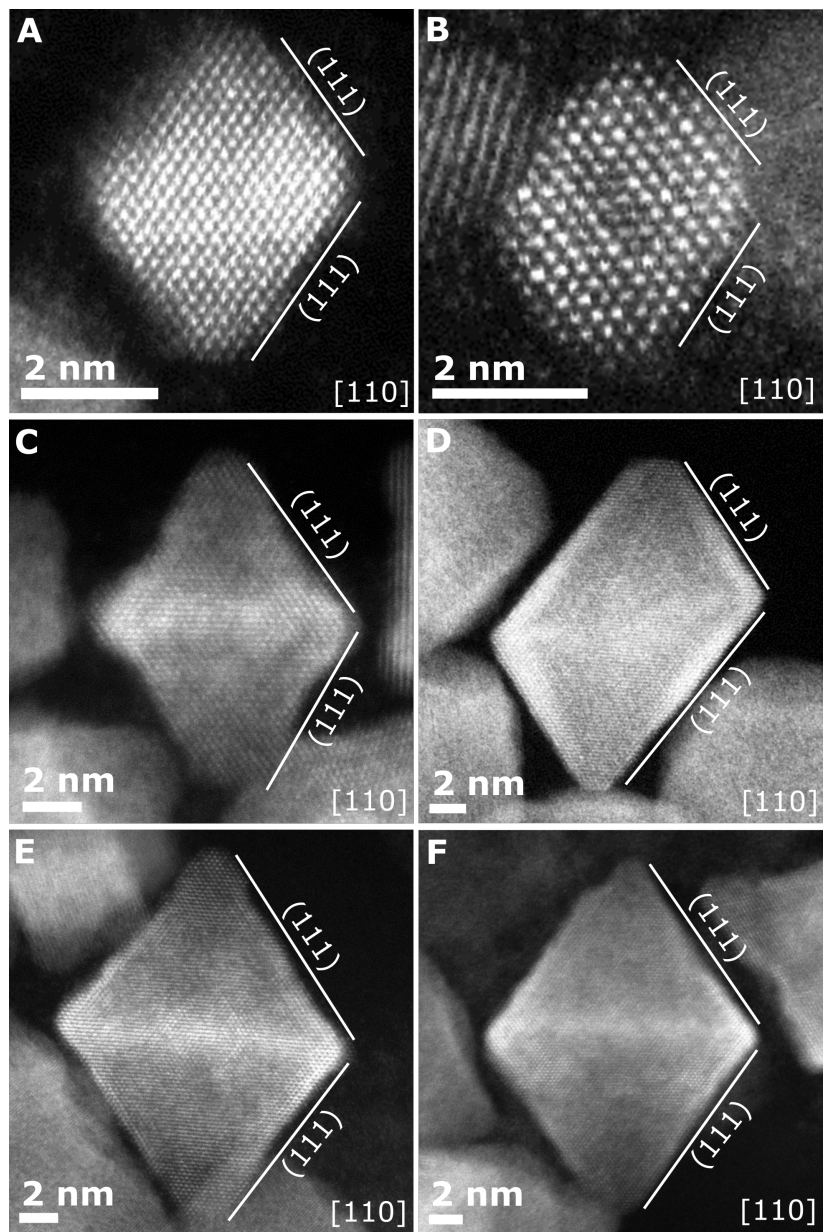

Figure 2. High-resolution STEM micrographs of PtNi nanoparticles formed with A) $\mathrm{Pt}(\mathrm{acac})_{2}$ and $\left.\mathrm{Ni}(\mathrm{acac})_{2}, \mathrm{C}\right) \mathrm{PtCl}_{4}$ and $\left.\mathrm{NiCl}_{2} \cdot 6 \mathrm{H}_{2} \mathrm{O}, \mathrm{E}\right) \mathrm{PtBr}_{4}$ and $\mathrm{NiBr}_{2} \cdot 2 \mathrm{H}_{2} \mathrm{O}$. B, D, and $\mathrm{F}$ are $\mathrm{PtCu}$ nanoparticles synthesized with $\mathrm{Pt}(\mathrm{acac})_{2}$ and $\mathrm{Cu}$ (acac) $)_{2}, \mathrm{PtCl}_{4}$ and $\mathrm{CuCl}_{2}$, and $\mathrm{PtBr}_{4}$ and $\mathrm{CuBr}_{2}$, respectively. The facet and zone axis assignments are based on FFT analysis from SI figure $\mathrm{S}_{5}$.

To understand the intensity differences in the HAADFSTEM images, the octahedra formed with $\mathrm{PtCl}_{4}$ and $\mathrm{CuCl}_{2}$ (PtCu-Cl) and with $\mathrm{PtBr}_{4}$ and $\mathrm{CuBr}_{2}$ (PtCu-Br) were investigated with STEM-EDS spectrum imaging. The elemental map of $\mathrm{PtCu}-\mathrm{Cl}$ and $\mathrm{PtCu}-\mathrm{Br}$ (Figure $3 \mathrm{~A}$ L) shows platinum enrichment on the surface of the na- noparticle and copper enrichment in the center (Figure 3 $\mathrm{C}-\mathrm{J}$ ), which is in agreement with the HAADF-STEM images. From the intensity line profiles, it can be seen that the platinum surface enrichment occurs $\sim 2 \mathrm{~nm}$ before the nanoparticle edge in both of the samples (Figure $3 \mathrm{~K}$ and $\mathrm{L}$ ). For $\mathrm{PtCu}-\mathrm{Br}$, the platinum intensity also shows an increase at the surface (Figure $3 \mathrm{~L}$ ). The platinumrich shell can be seen at all orientations (SI Figure S6). The results with PtNi also show a higher proportion of platinum at the surface (SI Figure $\mathrm{S} 7$ ).
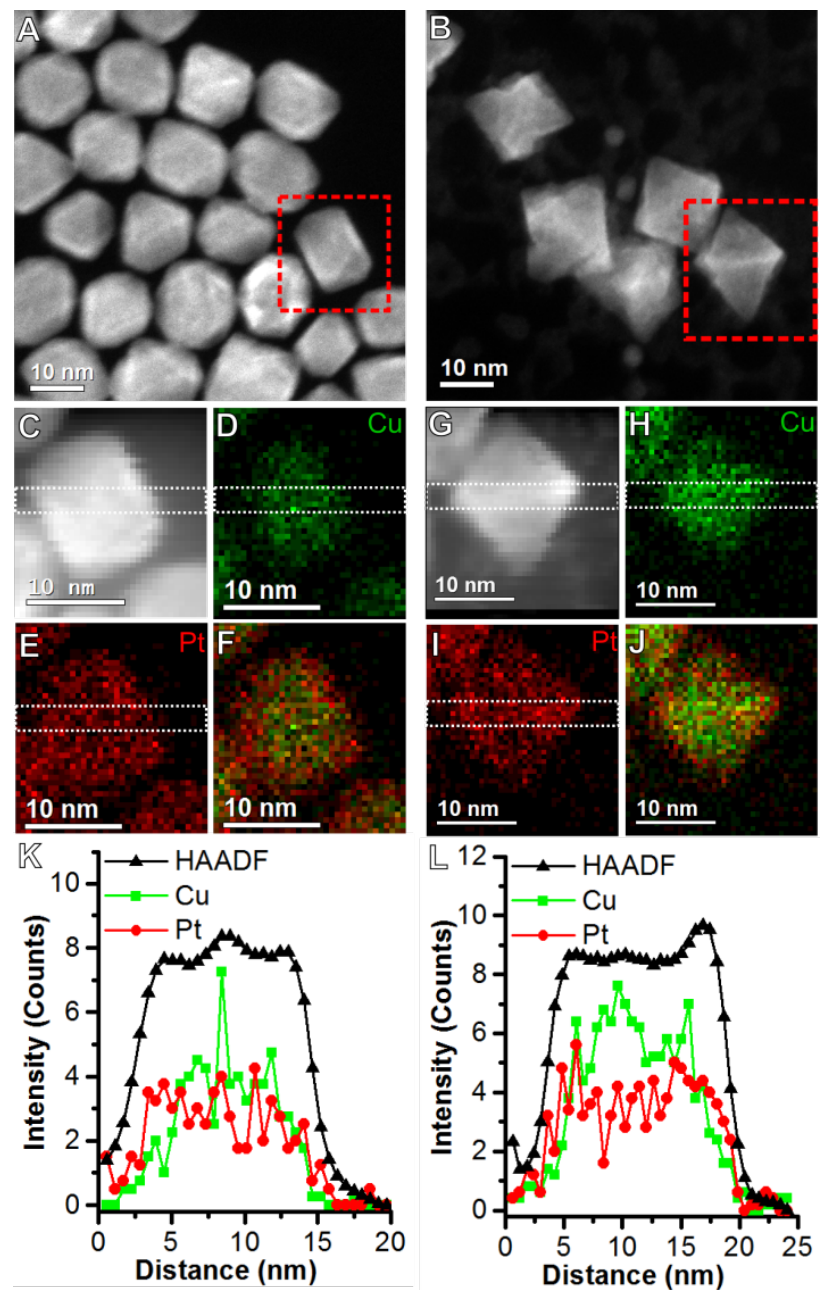

Figure 3. A and B are HAADF-STEM micrographs of $\mathrm{PtCu}$ nanoparticles formed from using $\mathrm{PtCl}_{4}$ and $\mathrm{CuCl}_{2}(\mathrm{PtCu}-\mathrm{Cl})$ as precursors and using $\mathrm{PtBr}_{4}$ and $\mathrm{CuBr}_{2}(\mathrm{PtCu}-\mathrm{Br})$ as precursors, respectively. The red dashed boxes indicate the area in which the spectrum image was obtained. The EDS map of A) is shown with $\mathrm{C}$ ) the HAADF-STEM signal, D) the $\mathrm{Cu} \mathrm{K}$ peak, E) the Pt L peak and F) the overlap. The EDS map of B) is shown with $\mathrm{G}$ ) the HAADF-STEM signal, $\mathrm{H}$ ) the $\mathrm{Cu} \mathrm{K}$ peak, I) the Pt L peak and J) the overlap. $\mathrm{K}$ and $\mathrm{L}$ are line profiles obtained from the white dashed box in $\mathrm{C}, \mathrm{D}$ and $\mathrm{E}$, and $\mathrm{G}, \mathrm{H}$, and I, respectively. The HAADF signal is in arbitrary units and is scaled to fit on the profile. 


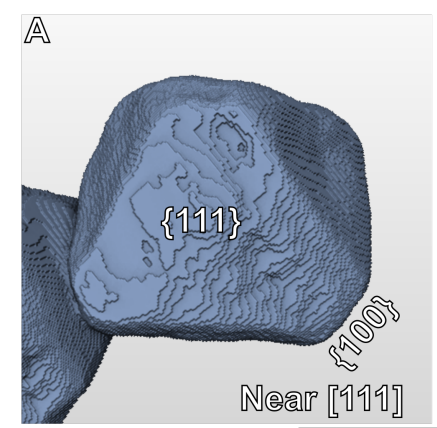

回
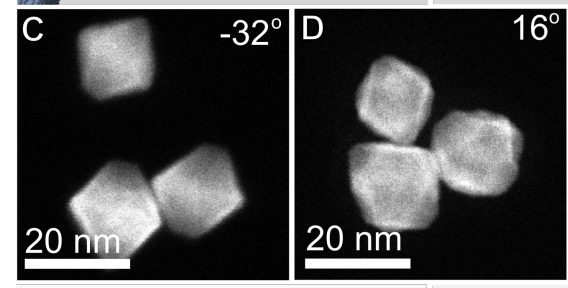

$16^{\circ} \mathrm{E}$

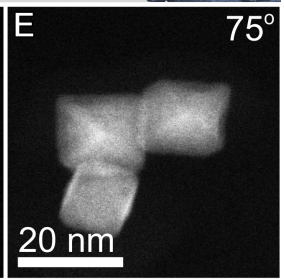

F
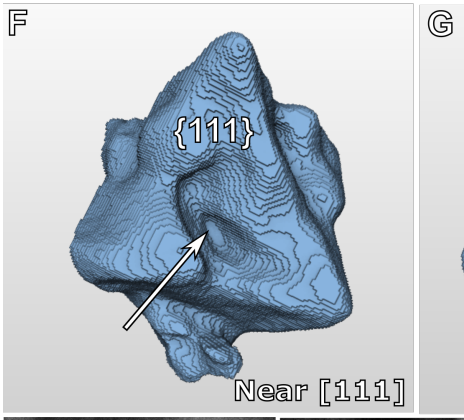

(G)

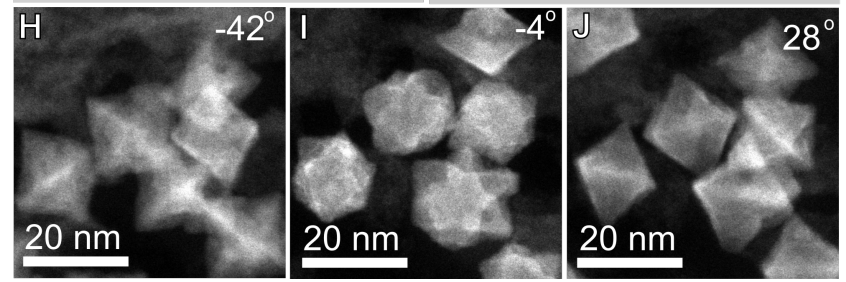

Figure 4. The nanoparticle shapes and volume rendered from the tomograms of a particle formed from $\mathrm{PtCl}_{4}$ and $\mathrm{CuCl}_{2}$ oriented near the A) [111] and B) [10o] zone axes. CE) TEM images from the tomoseries for A and B at -32, 16 and 75 degrees. The nanoparticle shapes and volume rendered from tomograms of a particle formed from $\mathrm{PtBr}_{4}$ and $\mathrm{CuBr}_{2}$ near the F) [111] and G) [100] zone directions. H-J) TEM images from the tomoseries for $\mathrm{F}$ and $\mathrm{G}$ at $-42,-4$ and 28 degrees.

To investigate the three dimensional surface morphology differences between the $\mathrm{PtCu}-\mathrm{Cl}$ sample and the $\mathrm{PtCu}-\mathrm{Br}$ sample, tomography was performed. The volume-reconstructed tomogram of $\mathrm{PtCu}-\mathrm{Cl}$ showed $\{111\}$ facets and slight truncation at its side corners, exposing the $\{100\}$ facet (Figure $4 \mathrm{~A}$ ). Near the [100] zone axis, the truncation at the top of the particle is due to anisotropy of the particle width (Figure $4 \mathrm{~B}-\mathrm{E}$ ). The volumeconstructed tomogram of $\mathrm{PtCu}-\mathrm{Br}$ (Figure $4 \mathrm{~F}$ ) shows unevenness and concavity into the $\{111\}$ surface facets to differing extents. The concavity into the four oriented $\{111\}$ facets is observable near the [100] zone axis (Figure $4 \mathrm{G}$ ). In the different angle projections of the nanoparticles from the $\mathrm{PtCu}-\mathrm{Br}$ sample (Figure $4 \mathrm{H}-\mathrm{J}$ ), the darker areas along the $\{111\}$ facets correspond to the uneven areas. The unevenness occurs as indentations along the $\{111\}$ facet of the octahedra; therefore, it is not obvious from all angles and is the most obvious near the [111] zone axis where the concave surface of the nanoparticles give the appearance of a hexagonal star structure (Figure 4 I).

The uneven facet structure is most prominent in the $\mathrm{PtCu}$ and PtNi nanoparticles formed with both of the bromide precursors (SI Figure S4) and therefore is postulated to occur because these samples have the highest concentration of bromide. Literature studies with $\mathrm{PtNi}$ octahedral have shown etching into the $\{111\}$ facets when exposed to oxygen, $4,13,32$ and using halide containing solvents. 4,13 Halides are commonly reported etchants in the presence of oxygen,33-34 and bromide has been reported to even etch noble metals, such as gold. $35-36$ The surface indentations can be minimized by performing the reaction under nitrogen (Figure S8); therefore, the surface structure is considered to arise from the oxidative etching by the $\mathrm{O}_{2} / \mathrm{Br}^{-}$pair. The surface indentations would create a higher-energy surface for chemical reactions than the pure $\{111\}$ faceted surfaces. 4,32

The elemental segregation observed with the formation of a platinum-rich shell is similar to observations reported in dealloying studies of $\mathrm{PtCu}^{14}$ and etching of PtNi octahedra. ${ }^{13}, 15,17,37$ Surface enrichment in single stage reactions could occur due to a sequential nucleation of one component before the other, $3^{8}$ adsorbate induced segregation, ${ }^{38}$ a galvanic replacement step ${ }^{38-39}$ or the etching of one element. The use of carbon monoxide gas has previously been considered to favor platinum surfaces due to the strong Pt-CO bond. ${ }^{40}$ The use of the less noble copper and nickel metals would also be susceptible to galvanic replacement by the $\mathrm{Pt}^{\mathrm{n}+}$ species and possible oxidative etching in solution. ${ }^{13-14}$ Surface rearrangement due to the carbon monoxide adsorbate as well as galvanic replacement and oxidative etching of the nanoparticles in solution is hypothesized to be occurring in this study. In this case the lower chemical stability of copper and nickel would lead to these metals being etched on the surface of the nanoparticle. The larger amount of segregation for copper would be due to the positive segregation energy to the surface for $\mathrm{Pt}$ in $\mathrm{PtCu} .{ }^{4}$

The XRD patterns of the particles synthesized from the different precursors showed a sharpening of the peaks, which is consistent with the increasing particle size when changing from the acetylacetonates to the chlorides and then to the bromides (Figure 5). There is also a shift to the right in the peak positions for the PtNi alloys (Figure $5 \mathrm{~A})$ as the particles become increasingly nickel rich when changing from the acetylacetonates to the chlorides and to the bromides. The $\mathrm{PtCu}$ alloys also showed a shift towards higher 2Theta values. The particle size via the Scherrer Equation fits closely for $\mathrm{Pt}(\mathrm{acac})_{2}+$ $\mathrm{Ni}(\mathrm{acac})_{2} \cdot 2 \mathrm{H}_{2} \mathrm{O}(4.4 \mathrm{~nm})$ and $\mathrm{Pt}(\mathrm{acac})_{2}+\mathrm{Cu}(\mathrm{acac})_{2}(3.1$ $\mathrm{nm})$. For the particles prepared from the halide precursor, asymmetry can be seen in the peaks, therefore fitting with two Gaussian components (Table $\mathrm{S}_{3}$ ). The asymmetry occurs due to a broader secondary peak at the lower 2Theta, arising from the platinum-rich shell. This shell is $1.6-3.7 \mathrm{~nm}$ for the PtNi particles and 3.5- 4.6 $\mathrm{nm}$ for the PtCu particles when changing from the chloride precursors to the bromides (Table S3). Similar 
asymmetry has been reported with dealloyed $\mathrm{PtCu}$ nanoparticles by Yang et al. ${ }^{15}$

The PtNi and PtCu alloys show an increasing ratio of the (111) reflection to the (200) and (220) reflections. This result is indicative nanoparticle ordering so that only the (111) plane is perpendicular to the X-ray source, which becomes more prominent with the larger particles as the particles become more aligned with their $\{111\}$ facet flat against the substrate. The larger particles would be less affected by the surface roughness of the XRD plates. In the PtCu system, as the etching becomes evident, there is an increase in the (200) reflection, indicating a reduction in ordering.
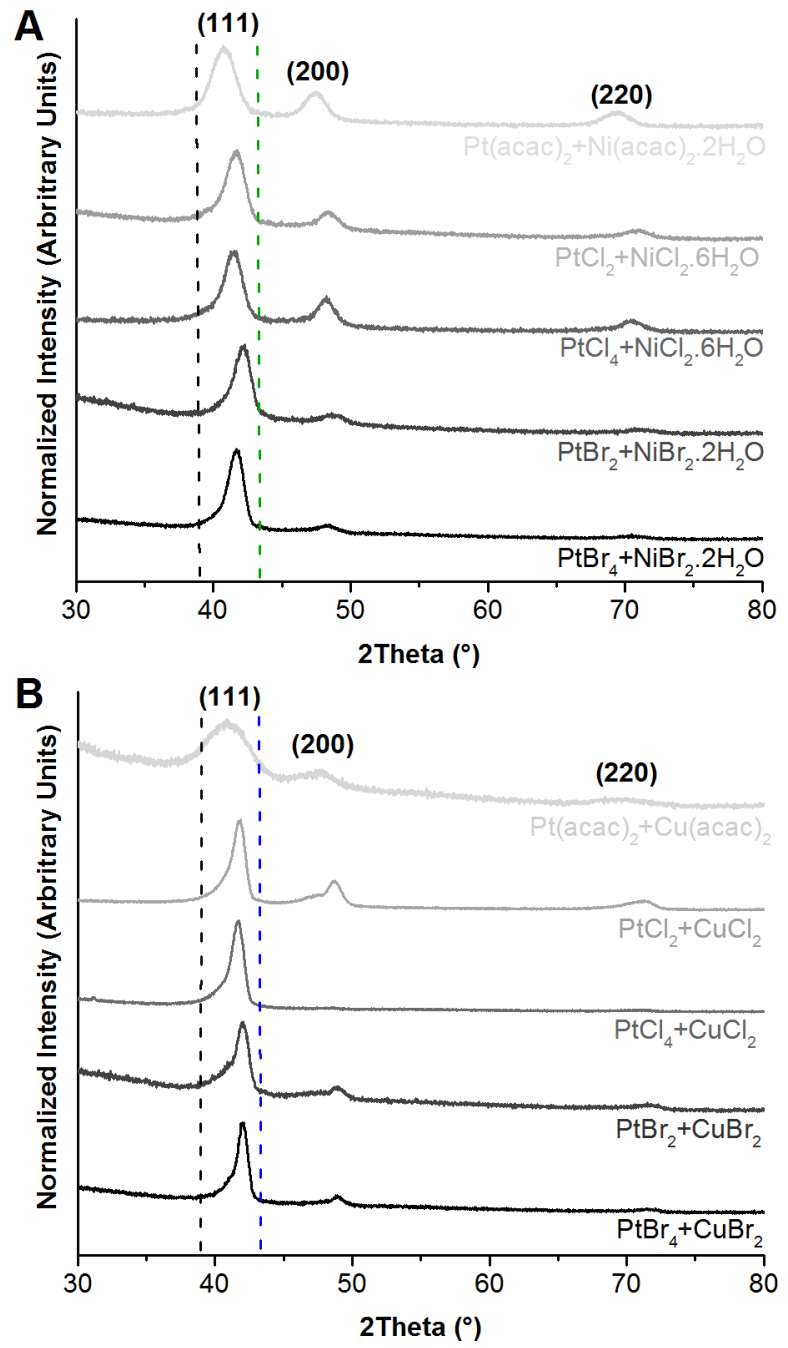

Figure 5. XRD patterns of $\mathrm{A}) \mathrm{PtNi}$ and $\mathrm{B}) \mathrm{PtCu}$ particles formed with the various precursors described in Figure 1. The dashed lines are guides for the Pt(111) peak in black, the $\mathrm{Ni}(111)$ peak in green and the $\mathrm{Cu}(111)$ peak in blue.

To understand the effect of both metal precursors on the particle size, we studied all of the precursor combinations (SI Figures S9-14 and Table S4-9). Looking first at the platinum precursors effect in the alloy synthesis, an obvious trend is seen across all of the precursor combinations with the nickel and the copper of an increasing particle size with $\mathrm{Pt}(\mathrm{acac})_{2}<\mathrm{PtCl}_{2}<\mathrm{PtCl}_{4}<\mathrm{PtBr}_{2}<\mathrm{PtBr}_{4}$
(Figure 6). This trend is not the same as that of the pure platinum in which the particle size increases from $\mathrm{Pt}$ (acac) $)_{2}<\mathrm{PtCl}_{4}<\mathrm{PtCl}_{2}<\mathrm{PtBr}_{4}<\mathrm{PtBr}_{2}$ (SI Figure $\mathrm{S}_{15}$ ). The trend for pure platinum mimics the halide stability of the platinum complexes. ${ }^{42}$ However, the effect of the Pt(IV) to $\mathrm{Pt}(\mathrm{II})$ in solution is reversed with respect to the findings of Yang et al. in polar solvents ${ }^{11}$ and is hypothesized to be due to the stability of the Pt(IV) ion vs. the Pt(II) ion in non-polar solvents. The effect of the secondary metal would be due to the increasingly negative standard reduction potentials of platinum, causing a rapid reoxidation of the reduced nickel or copper species, while only reducing half the amount of metallic platinum.

The halides introduced by the platinum precursor show a linear relationship with the size of the PtNi system (Figure $6 \mathrm{~A}$ ), with the bromide ions having a greater effect than the chloride ions. This general effect on the size of the nickel or copper precursor is $\mathrm{Ni}$ (acac) $)_{2} \cdot 2 \mathrm{H}_{2} \mathrm{O}$ $<\mathrm{NiCl}_{2} \cdot 6 \mathrm{H}_{2} \mathrm{O}<\mathrm{NiBr}_{2} \cdot 2 \mathrm{H}_{2} \mathrm{O}$ (Figure 6A), and $\mathrm{Cu}(\text { acac) })_{2}$ $<\mathrm{CuX}_{2}$, where $\mathrm{CuBr}_{2}$ and $\mathrm{CuCl}_{2}$ are within the error of each other (Figure $6 \mathrm{~B}$ ).

Size control with the precursors in the PtNi system is based on the concentration of halides used and increases nearly linearly with halide addition (Figure $6 \mathrm{~A}$ ). This can be seen as the size of the particles produced from the mixed precursors are the same if the platinum and nickel salts are reversed, for example, the particles formed with $\mathrm{Pt}(\text { acac })_{2}$ and $\mathrm{NiCl}_{2} \cdot 6 \mathrm{H}_{2} \mathrm{O}$ are within error of those produced from $\mathrm{PtCl}_{2}$ and $\mathrm{Ni}$ (acac) $)_{2} \cdot 2 \mathrm{H}_{2} \mathrm{O}$. We propose that the nickel precursors undergo mixing of their ligand shells in solution with the oleylamine substituting the halides, in contrast to the copper precursors in which the ligands modify the precursor structure (Figure S16). The oleylamine is also considered to displace the original aqua ligands around the nickel precursor, as the oleylamine is in excess to the waters of hydration. It should also be noted that nickel readily forms a carbonyl,7, 43 which would further alter the nickel precursor during the synthesis, causing the displacement of the halide species and possibly interacting with platinum.

Across all of the nanoparticle systems, there is a trend towards lower Pt:Ni ratios when using the halides, with the lowest values using $\mathrm{PtBr}_{4}$ (Figure $\mathrm{S} 17 \mathrm{~A}$ ). For the $\mathrm{PtCu}$ particles, there is slight decrease in the $\mathrm{Pt}: \mathrm{Cu}$ values when using $\mathrm{PtBr}_{4}$, but the $\mathrm{Pt}: \mathrm{Cu}$ ratio does not vary, displaying an obvious trend with the different precursors (Figure S17 B). 

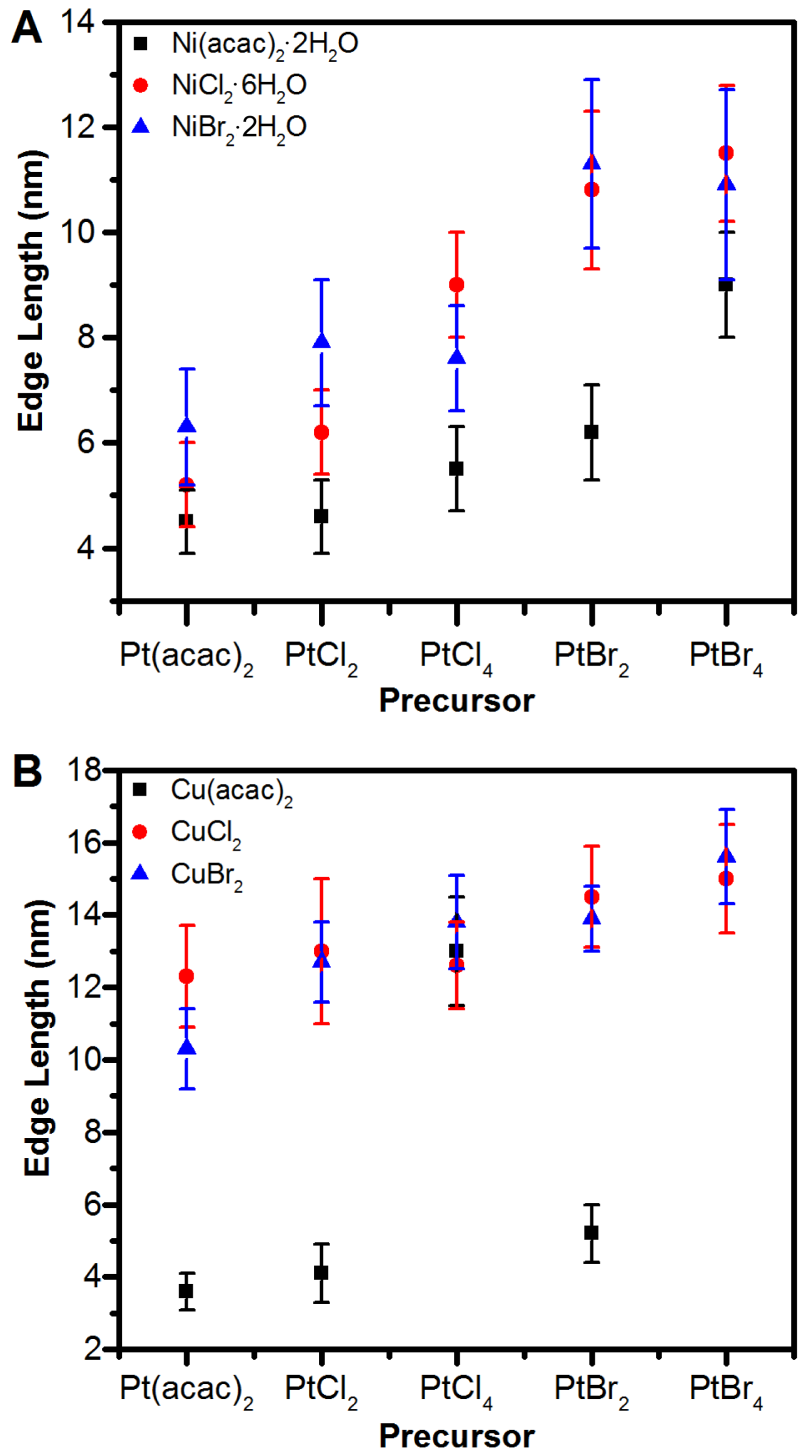

Figure 6. The graph of the effect of both precursors on the nanoparticle edge length shown with A) nickel and B) copper.

The systems studied show that even when altering the reduction kinetics of the precursors individually the nanoparticle alloys are still formed. This is considered to be due to the interplay between the two precursors in solution via galvanic replacement and diffusion of the metals over time. The effects of galvanic replacement of the $\mathrm{Ni}(\mathrm{II})$ or $\mathrm{Cu}(\mathrm{II})$ with the Pt(IV) precursors could theoretically oxidize twice the amount of copper or nickel into solution compared with $\mathrm{Pt}(\mathrm{II})$, thus reducing the number of initial nuclei. The halides would alter the equilibrium between $\mathrm{M}^{\mathrm{o}}$ and $\mathrm{M}^{\mathrm{n}+}$ slowing the reduction process and increasing re-oxidation of the metals into solution. The halide ligands also form compounds that decrease the reduction rate of the platinum precursors by decreasing reduction potentials in analogy to the findings of Mirkin et al. with gold. $44-45$

In contrast to previous works with halides, $44-45$ we did not observe a noticeable halide effect on the surface faceting of the octahedral or residual halides on their sur- face (Figure S18). This is thought to be due to the fact that the carbon monoxide injected with $\mathrm{W}(\mathrm{CO})_{6}$ is in excess by three times the maximum amount of halides added. However, the halide ligands have a large effect on the elemental composition of the nanoparticle surface, causing an enrichment of the surface in all the cases and a high degree of etching upon the introduction of bromides in the presence of oxygen.

The observed effects of the precursor ligands and surfactants in this study are compared to the five major ways ligands and surfactants could act on the nucleation and growth of nanoparticles outlined by Ortiz and Skrabalak. These in short are by (i) effecting the coordination of the metal centers determining the initial stability of the reduction step, (ii) the coordination to the growing surface of the nanoparticle effecting it's colloidal stability, (iii) the coordination to the surface determining the atom addition and thus facet stability, (iv) the possible ability for the surfactant or ligand to act as a reducing agent or (v) as an oxidative etchant. ${ }^{21}$ In this study we have shown that the initial ligands for the precursors determine the initial stability of the metal center for platinum and copper precursors and not the nickel. This appears to be due to the oleylamine and carbon monoxide replacing the ligands of the nickel. The oleylamine and carbon monoxide would determine the colloidal stability and also dominate the surface interactions for the nanoparticles growth directions and reducing behavior. The halides would still interact to some degree with the surface during growth and is predicted to act as an etchant with oxygen shifting the equilibrium between the $\mathrm{M}^{\mathrm{n}+}$ in the solution and $\mathrm{M}^{\circ}$ in the nanoparticle.

\section{CONCLUSIONS}

The approach described in this article is completely scalable and can be run continuously to allow production of these particles on an industrial scale. The method enables control of the nanoparticle size and the degree of surface segregation of the nanoparticle alloys formed by selecting the ligand shell of the precursors used in the reaction. The particles were readily tuned from $3-16$ $\mathrm{nm}$ with $\mathrm{PtCu}$ and from $4-11 \mathrm{~nm}$ with PtNi. The final particle size increases while changing the ligands from acac $<\mathrm{Cl}<\mathrm{Br}$ in all cases and when moving from $\mathrm{Pt}(\mathrm{II})<\mathrm{Pt}(\mathrm{IV})$ in the bimetallic systems. The nanoparticle size is much more sensitive to the copper precursor than the nickel precursor and this is predicted to be due to the oleylamine displacing the halide ligands before the reaction. In this reaction system, the carbon monoxide dominates the formation of the surface facets during the reaction, but the choice of starting ligands around the precursor affects the size of the overall particle and the surface composition of the nanoparticles formed. The larger octahedra formed with the halide precursors are shown to have surface enrichment of platinum on their surfaces. The use of bromides as precursors gives rise to indentations on the $\{111\}$ facets of the octahedra leading to an open surface structure. The precursor effect is seen in both platinum-copper and platinum-nickel alloys and is thought to be due to the galvanic replacement process occurring in solution and the difference in the standard electrode potentials between platinum and nickel or copper. The use of acetylacetonate and halides to control the nanoparticle size and surface segregation of metals 
introduces a robust approach to controlling nanoparticle alloys.

\section{AUTHOR INFORMATION}

\section{Corresponding Author \\ * Osman.bakr@kaust.edu.sa}

\section{Present Address}

A.P.L. JEOL Nanocentre and Department of Physics, University of York, UK

\section{Author Contributions}

All of the authors contributed to the preparation of the manuscript. All of the authors approved the final version of the manuscript. KRK designed the synthetic procedure for the flow reactor. APL, NA and KRK synthesized the halide precursors. APL performed TEM, STEM and STEM-EDS mapping. NA, KRK, and APL performed XRD. APL and DHA performed tomography. APL hypothesized the growth mechanism. APL wrote the manuscript and carried out the analysis. APL, NA, OMB, KRK, and DHA contributed to the discussion and interpretation of results.

$\Omega$ These authors contributed equally.

\section{Notes}

The authors declare no competing financial interests.

\section{ASSOCIATED CONTENT}

Supporting Information. Additional HAADF-STEM images, EELS, EDS, EDS Spectrum image maps, TEM images, sizes and EDS ratios, Sizes obtained from the Scherrer equation, and UV/Vis spectra of nickel and copper precursor solutions. This information is available free of charge via the Internet at http://pubs.acs.org.

\section{REFERENCES}

(1) An, K.; Somorjai, G. A., Size and Shape Control of Metal Nanoparticles for Reaction Selectivity in Catalysis. ChemCatChem 2012, 4, 1512-1524.

(2) Burda, C.; Chen, X. B.; Narayanan, R.; El-Sayed, M. A., Chemistry and properties of nanocrystals of different shapes. Chem. Rev. 2005, 105, 1025-1102.

(3) Aiken, J. D.; Finke, R. G., A review of modern transitionmetal nanoclusters: their synthesis, characterization, and applications in catalysis. J. Mol. Catal. A: Chem. 1999, 145, 144.

(4) Chen, C.; Kang, Y.; Huo, Z.; Zhu, Z.; Huang, W.; Xin, H. L.; Snyder, J. D.; Li, D.; Herron, J. A.; Mavrikakis, M.; Chi, M.; More, K. L.; Li, Y.; Markovic, N. M.; Somorjai, G. A.; Yang, P.; Stamenkovic, V. R., Highly Crystalline Multimetallic Nanoframes with Three-Dimensional Electrocatalytic Surfaces. Science 2014, 343, 1339-1343.

(5) Choi, S.-I.; Xie, S.; Shao, M.; Odell, J. H.; Lu, N.; Peng, H.-C.; Protsailo, L.; Guerrero, S.; Park, J.; Xia, X.; Wang, J.; Kim, M. J.; Xia, Y., Synthesis and Characterization of $9 \mathrm{~nm} \mathrm{Pt-}$ Ni Octahedra with a Record High Activity of $3.3 \mathrm{~A} / \mathrm{mgPt}$ for the Oxygen Reduction Reaction. Nano Lett. 2013, 13, 3420-3425.

(6) Zhang, J.; Yang, H.; Fang, J.; Zou, S., Synthesis and Oxygen Reduction Activity of Shape-Controlled $\mathrm{Pt}_{3} \mathrm{Ni}$ Nanopolyhedra. Nano Lett. 2010, 10, 638-644.

(7) Cui, C.; Gan, L.; Neumann, M.; Heggen, M.; Roldan Cuenya, B.; Strasser, P., Carbon Monoxide-Assisted Size Confinement of Bimetallic Alloy Nanoparticles. J. Am. Chem. Soc. 2014, 136, 4813-4816.
(8) Wu, J.; Qi, L.; You, H.; Gross, A.; Li, J.; Yang, H. Icosahedral Platinum Alloy Nanocrystals with Enhanced Electrocatalytic Activities. J. Am. Chem. Soc. 2012, 134, 1188011883.

(9) Choi, S.-I.; Xie, S.; Shao, M.; Lu, N.; Guerrero, S.; Odell, J. H.; Park, J.; Wang, J.; Kim, M. J.; Xia, Y., Controlling the Size and Composition of Nanosized Pt-Ni Octahedra to Optimize Their Catalytic Activities toward the Oxygen Reduction Reaction. ChemSusChem 2014, 7, 1476-1483.

(10) Wettergren, K.; Hellman, A.; Cavalca, F.; Zhdanov, V. P.; Langhammer, C., Unravelling the Dependence of Hydrogen Oxidation Kinetics on the Size of Pt Nanoparticles by in Operando Nanoplasmonic Temperature Sensing. Nano Lett. 2015, 15, 574-580.

(11) Tsung, C.-K.; Kuhn, J. N.; Huang, W.; Aliaga, C.; Hung, L.-I.; Somorjai, G. A.; Yang, P., Sub-10 nm Platinum Nanocrystals with Size and Shape Control: Catalytic Study for Ethylene and Pyrrole Hydrogenation. J. Am. Chem. Soc. 2oo9, $131,5816-5822$.

(12) Kuhn, J. N.; Huang, W.; Tsung, C.-K.; Zhang, Y.; Somorjai, G. A., Structure Sensitivity of Carbon-Nitrogen Ring Opening: Impact of Platinum Particle Size from below 1 to $5 \mathrm{~nm}$ upon Pyrrole Hydrogenation Product Selectivity over Monodisperse Platinum Nanoparticles Loaded onto Mesoporous Silica. J. Am. Chem. Soc. 2008, 130, 1402614027.

(13) Cui, C.; Gan, L.; Heggen, M.; Rudi, S.; Strasser, P., Compositional segregation in shaped Pt alloy nanoparticles and their structural behaviour during electrocatalysis. Nat. Mater. $\mathbf{2 0 1 3}, 12,765-771$.

(14) Strasser, P.; Koh, S.; Anniyev, T.; Greeley, J.; More, K.; Yu, C.; Liu, Z.; Kaya, S.; Nordlund, D.; Ogasawara, H.; Toney, M. F.; Nilsson, A., Lattice-strain control of the activity in dealloyed core-shell fuel cell catalysts. Nat. Chem. 2010, 2, 454-46o.

(15) Yang, R.; Leisch, J.; Strasser, P.; Toney, M. F., Structure of Dealloyed $\mathrm{PtCu}_{3}$ Thin Films and Catalytic Activity for Oxygen Reduction. Chem. Mater. 2010, 22, 4712-4720.

(16) Patrick, B.; Ham, H. C.; Shao-Horn, Y.; Allard, L. F.; Hwang, G. S.; Ferreira, P. J., Atomic Structure and Composition of " $\mathrm{Pt}_{3} \mathrm{Co}$ " Nanocatalysts in Fuel Cells: An Aberration-Corrected STEM HAADF Study. Chem. Mater. 2013, 25, 530-535.

(17) Gan, L.; Cui, C.; Heggen, M.; Dionigi, F.; Rudi, S.; Strasser, P., Element-specific anisotropic growth of shaped platinum alloy nanocrystals. Science 2014, 346, 1502-1506.

(18) Ortiz, N.; Weiner, R. G.; Skrabalak, S. E., LigandControlled Co-reduction versus Electroless Co-deposition: Synthesis of Nanodendrites with Spatially Defined Bimetallic Distributions. ACS Nano 2014, 8, 12461-12467.

(19) LaGrow, A. P.; Ingham, B.; Toney, M. F.; Tilley, R. D., Effect of Surfactant Concentration and Aggregation on the Growth Kinetics of Nickel Nanoparticles. J. Phys. Chem. C 2013, 117, 16709-16718.

(20) van Embden, J.; Mulvaney, P., Nucleation and Growth of CdSe Nanocrystals in a Binary Ligand System. Langmuir 2005, 21, 10226-10233.

(21) Ortiz, N.; Skrabalak, S. E., On the Dual Roles of Ligands in the Synthesis of Colloidal Metal Nanostructures. Langmuir 2014, 3o, 6649-6659.

(22) Ortiz, N.; Skrabalak, S. E., Manipulating Local Ligand Environments for the Controlled Nucleation of Metal Nanoparticles and their Assembly into Nanodendrites. Angew. Chem. Int. Ed. 2012, 51, 11757-11761.

(23) Knudsen, K. R.; Holden, J.; Ley, S. V.; Ladlow, M., Optimisation of conditions for O-benzyl and Nbenzyloxycarbonyl protecting group removal using an automated flow hydrogenator. Adv. Synth. Catal. 2007, 349, 535-538.

(24) Rahbek Knudsen, K.; Ladlow, M.; Bandpey, Z.; Ley, S., Fully Automated Sequence-Specific Synthesis of a-Peptides Using Flow Chemistry. J. Flow Chem. 2014, 4, 18-21. 
(25) Mehenni, H.; Lutfan, S.; Mahfouz, R.; Katsiev, K.; Bakr, O. M., Rapid continuous flow synthesis of high-quality silver nanocubes and nanospheres. RSC Adv. 2013, 3, 22397-22403.

(26) Wu, J.; Gross, A.; Yang, H., Shape and CompositionControlled Platinum Alloy Nanocrystals Using Carbon Monoxide as Reducing Agent. Nano Lett. 2011, 11, 798-802.

(27) Zhang, J.; Fang, J., A General Strategy for Preparation of Pt 3d-Transition Metal (Co, Fe, Ni) Nanocubes. J. Am. Chem. Soc. 2009, 131, 18543-18547.

(28) Kang, Y.; Ye, X.; Murray, C. B., Size- and ShapeSelective Synthesis of Metal Nanocrystals and Nanowires Using $\mathrm{CO}$ as a Reducing Agent. Angew. Chem. Int. Ed. 2010, 49, 6156-6159.

(29) Wu, B.; Zheng, N.; Fu, G., Small molecules control the formation of Pt nanocrystals: a key role of carbon monoxide in the synthesis of Pt nanocubes. Chem. Commun. 2011, 47, 10391041.

(30) Zhang, J.; Luo, Z.; Martens, B.; Quan, Z.; Kumbhar, A.; Porter, N.; Wang, Y.; Smilgies, D.-M.; Fang, J., Reversible Kirkwood-Alder Transition Observed in $\mathrm{Pt}_{3} \mathrm{Cu}_{2}$ Nanoctahedron Assemblies under Controlled Solvent Annealing/Drying Conditions. J. Am. Chem. Soc. 2012, 134, 14043-14049.

(31) Kang, Y.; Pyo, J. B.; Ye, X.; Diaz, R. E.; Gordon, T. R.; Stach, E. A.; Murray, C. B., Shape-Controlled Synthesis of Pt Nanocrystals: The Role of Metal Carbonyls. ACS Nano 2013, 7 , 645-653.

(32) Wu, Y.; Wang, D.; Niu, Z.; Chen, P.; Zhou, G.; Li, Y., A Strategy for Designing a Concave Pt-Ni Alloy through Controllable Chemical Etching. Angew. Chem. Int. Ed. 2012, 51, 12524-12528.

(33) Wiley, B.; Herricks, T.; Sun, Y.; Xia, Y., Polyol Synthesis of Silver Nanoparticles: Use of Chloride and Oxygen to Promote the Formation of Single-Crystal, Truncated Cubes and Tetrahedrons. Nano Lett. 2oo4, 4, 1733-1739.

(34) Xiong, Y.; Chen, J.; Wiley, B.; Xia, Y.; Aloni, S.; Yin, Y., Understanding the Role of Oxidative Etching in the Polyol Synthesis of Pd Nanoparticles with Uniform Shape and Size. $J$. Am. Chem. Soc. 2005, 127, 7332-7333.
(35) Soejima, T.; Kimizuka, N., One-Pot Room-Temperature Synthesis of Single-Crystalline Gold Nanocorolla in Water. $J$. Am. Chem. Soc. 2009, 131, 14407-14412.

(36) Hong, J. W.; Lee, Y. W.; Kim, M.; Kang, S. W.; Han, S. W., One-pot synthesis and electrocatalytic activity of octapodal $\mathrm{Au}-\mathrm{Pd}$ nanoparticles. Chem. Commun. 2011, 47, 2553-2555.

(37) Cui, C.; Gan, L.; Li, H.-H.; Yu, S.-H.; Heggen, M.; Strasser, P., Octahedral PtNi Nanoparticle Catalysts: Exceptional Oxygen Reduction Activity by Tuning the Alloy Particle Surface Composition. Nano Lett. 2012, 12, 5885-5889.

(38) Oezaslan, M.; Hasché, F.; Strasser, P., Pt-Based CoreShell Catalyst Architectures for Oxygen Fuel Cell Electrodes. $J$. Phys. Chem. Lett. 2013, 4, 3273-3291.

(39) Strasser, P.; Koh, S.; Greeley, J., Voltammetric surface dealloying of Pt bimetallic nanoparticles: an experimental and DFT computational analysis. Phys. Chem. Chem. Phys. 2oo8, $10,3670-3683$.

(40) Mayrhofer, K. J. J.; Juhart, V.; Hartl, K.; Hanzlik, M.; Arenz, M., Adsorbate-Induced Surface Segregation for CoreShell Nanocatalysts. Angew. Chem. Int. Ed. 2009, 48, 35293531 .

(41) Wang, L. L.; Johnson, D. D., Predicted Trends of CoreShell Preferences for 132 Late Transition-Metal Binary-Alloy Nanoparticles. J. Am. Chem. Soc. 2009, 131, 14023-14029.

(42) Poe, A. J.; Vaidya, M. S., 691. The relative stabilities of halogeno-complexes. Part I. The hexahalogenoplatinates. $J$. Chem. Soc. 1960, 3431-3436.

(43) Mittasch, A., Über Eisencarbonyl und Carbonyleisen. Angew. Chem. 1928, 41, 827-833.

(44) Millstone, J. E.; Wei, W.; Jones, M. R.; Yoo, H.; Mirkin, C. A., Iodide Ions Control Seed-Mediated Growth of Anisotropic Gold Nanoparticles. Nano Lett. 2oo8, 8, 25262529.

(45) Langille, M. R.; Personick, M. L.; Zhang, J.; Mirkin, C. A., Defining Rules for the Shape Evolution of Gold Nanoparticles. J. Am. Chem. Soc. 2012, 134, 14542-14554. 
Authors are required to submit a graphic entry for the Table of Contents (TOC) that, in conjunction with the manuscript title, should give the reader a representative idea of one of the following: A key structure, reaction, equation, concept, or theorem, etc., that is discussed in the manuscript. Consult the journal's Instructions for Authors for TOC graphic specifications.

Insert Table of Contents artwork here

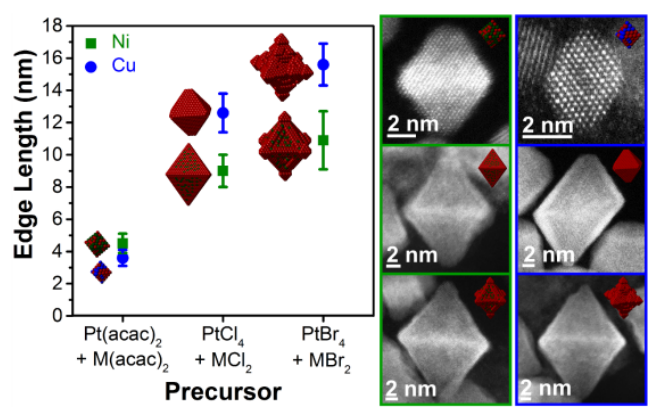

